\title{
Characteristics of the Morphological Identity of Ancient Buildings from the Perspective of Christopher Alexander; Case Study of Boushehr Old Tissue
}

\author{
Maryam Merajodin \\ Department of Architecture, Islamic Azad University Boushehr Branch, Boushehr, Iran
}

Email address:

Maryam.meraj@yahoo.com

\section{To cite this article:}

Maryam Merajodin. Characteristics of the Morphological Identity of Ancient Buildings from the Perspective of Christopher Alexander; Case Study of Boushehr Old Tissue. International Journal of Science, Technology and Society. Special Issue: Research and Practice in Architecture and Urban Studies in Developing Countries. Vol. 3, No. 2-1, 2015, pp. 132-137. doi: 10.11648/j.ijsts.s.2015030201.35

\begin{abstract}
Similarities between cities and buildings in past times is far more than similarities among buildings that are built today. Christopher Alexander believes that the common part, is the morphological identity and have its own characteristics. In this article the correspondence between morphological identity of Bushehr architecture and Alexander's theory has been studied. The purpose is recognition of Bushehr architecture and its manifestations. In this regard content analysis, spatial Analysis and visual analysis have been used. The research indicates that the Characteristics of morphological identity in ancient buildings, mentioned by Alexander, is seen in Bushehr architecture.
\end{abstract}

Keywords: Identity, Architecture, Old Tissu, Boushehr

\section{Introduction}

The method of designing in architecture was not always the same. A few centuries ago, a craftsman and an employer agreed to raise a building without drawing a plan. A brief discussion about the orientation of building and other minor things was enough. Spatial models of building and methods of construction rarely were changed. The window in a building might have been different from other building but the proportion and type of construction, location and thickness of the walls were the same. They were constructing according to the rules of art. Unspoken and unwritten agreements were between craftsmen and designers in each area [1].

In the past people did not see the need to determine their identity because their place in the mortal world, the society and the country was specified. They were not aware of global events and their values and norms were not changed by Time compression of developments in communication. But when everything became fast, they realized that everything is changing and all those things which seemed rigid and firm is diminishing. So the issue of identity became one of the main concerns of modern people. The world is not static for human anymore and has the ability of changing by modern human [2].

The views expressed on identity in field of architecture can be put into three categories. The first category which account for a higher volume, contains arguments that raise the issue of identity in theoretical field by relying on different sciences such as economics, philosophy and politics. The second category is arguments with emotional and nostalgic attitude about identity issue. In these arguments identity is something that existed in the past and today is gone. Therefore praising the past and trying to get back to it, is the main core of these discussions. The third group discuss by architectural vision and argue according to specific tools of this field. For this reason they have the capacity of attracting audience from various fields. Most of the theories in this category raise within another field. Alexander's theory about morphological identity, stands in third category.

\section{Theory}

Christopher Alexander sort the buildings of the world into two categories. He puts "in the one pile, all those traditional buildings, built for thousands of years, in traditional societies all over the world and in the other pile, all those buildings built in the last hundred years, built by totalitarian technology, by industry." He believes that "traditional buildings have been built by pattern languages. The advantage of using languages does not just help to root our buildings in reality; does not just 
guarantee that they meet human needs; that they are congruent with forces lying in them- it makes them to be fundamentally different in viewpoint." In order to make this deference precise, he states that "although traditional buildings have vast variety of different forms still compared with the other pile, they have something in common. It is a particular morphological identity [3]. He has mentioned characteristics for this identity, which is coming below:

1. Patterns

2. More variety and more details rather than new buildings

3. Balance between order and disorder

4. Sharpness, freedom and special atmosphere

5. It is not necessarily complicated or simple

6. Each part becomes whole in its own terms

7. Reflecting the forces in them properly

\section{Case Study}

The old tissue of Bushehr, experienced, many ups and downs throughout history and has gone through many changes These changes led to the gradual expansion of the initial core of the city and turned it into a big city [4].

Bushehr has a mysterious history. Bushehr native scientists research into the history of the city indicates that the archaism of Bushehr back to "Ilam" era. Archeologist's Documents and findings in "Shoghab" cemetery of Bushehr, "Ryshehr" castle, "Charkhab" archaeological site, "Bardak e siah" archaeological site and "Siraf" historical and archaeological site fully confirm these research. These sites and monuments certainly indicate that this region was home to Iranian's civilization and life since the "Ilam" era until now [5]. The city of Bushehr is divided into two parts. One part of it is located in the north and the other part is in the south of city. Between these two parts, there are garrisons and military spaces which makes about three quarters of the city. The southern part, has much older history, and it has been one of the first life settings in Bushehr. The northern part which is our discussion issue, was formed from "Naderi" era to establish the naval base of Iran [5].

Many ancient cities in Iran have formed around a center that includes governmental, commercial and religious buildings. Bazar usually reaches to this center or starts from this center. This reflects the authoritarian thought in the urban structure. This pattern of urbanization can be seen in many cities such as Kashan, Isfahan and Yazd but such a pattern is not seen in Bushehr. Bazar is not, as it is in other cities, like a thread which connect urban grains together. Profession and guilds are distributed in four districts of city [6].

Extraversion and having the lowest common sides with next- door buildings in order to achieve most of the air flow, have sorted the texture of city into blocks, each made up of one or more residential units. Interconnected blocks with irregular alleys between them, that cross the little squares and finally reach to sea, shape the texture of city [7]. In contrast to districts that are mostly defined by social boundaries, blocks have definite boundaries that are surrounded by streets. Most of the characteristics of district system has maintained until now. Despite the separation of texture by Enghelab
Street, the sense of belonging to district can be seen in social customs especially mourning days [8]. These districts include "Behbahani" neighborhood, "Couty" neighborhood, "Shnbedy" neighborhood and "Dehdashti" neighborhood.

Bushehr architecture is known by some important characteristics: the building works both with inside and outside Unlike the closed architecture of most parts of Iran especially architecture of cities around the desert, that all the aesthetic aspects belongs to inside not outside; In Bushehr architecture, architect designs without any unessential symmetry and rigidity and Changes the form and volume anywhere it's necessary. It can be bravely claimed that symmetry in plan and volume is rarely found. Bushehr architecture is the perfect composition of Open, semi-open and closed spaces, or the public, semi-public and private spaces [9].

Because of being near the sea, high level of ground water and high humidity, basement is not seen in Bushehr architecture and ground floor which includes spaces such as kitchen and store has servicing role while the first and second floors are mostly residential. Advantage of the higher floors, is easier ventilation. Also in these floors windows are safe from passers sight and the privacy of inner spaces is preserved [10].

\section{Characteristics of Morphological Identity}

\subsection{Patterns}

"This character is marked, to start with, by the patterns underlying it. Low buildings; open stairs leading to upper floors; long tables with communal eating; roofs which are either pitched or domed, large and visible, or else used as terraces; rooms placed so that the light floods into them from two sides at least; gardens made for smelling and touching flowers not only seeing them; water still and moving; arcades along the edge of buildings; porches between buildings and gardens; small public and private squares, with arcades and porches at their edges; galleries at upper levels; columns at the corners of the rooms and spaces; ceilings at different heights according to the intimacy of rooms; small alcoves at the edges of rooms, trellises covered by roses and vines; walls in which possessions and decorations show the character of life and fill the room with it; communities separated from one another by substantial boundaries, so that each one can live in its own way, unhampered by the others [3]."

Many of the patterns in bushehr architecture is related to the open and semi- open spaces. Semi- open spaces which are a part of building's volume and are located between rooms and courtyard or between rooms and outdoor space; are known as "Tarmeh". Semi open spaces which are outside of buildings surface are known as "Shenashir". Other patterns of open spaces, are roof gardens or roofs which are often used in hot nights of the year. These roofs have short walls around them, made of wooden shutters or fences. Central courtyards as semi- open spaces often have geometrical regularity but not in all cases. In some of them pool, garden and sometimes trees 
such as banana and orange is seen.

Rooms can be divided into two categories: rooms for living in summer and living in winter. Summer living rooms are on the upper floors and their windows open either to the outdoor spaces (in some cases to the sea) and inside spaces. Winter living rooms are located on the lower floors and have windows to the inside spaces and work with a central courtyard. Rooms have way to each other. Size of the rooms and their geometry is different. In some cases rooms doesn't have a specific geometry. Living rooms are larger and have more windows.

\subsection{More Variety and More Details Rather Than New Buildings}

"It is marked by greater differentiation. If we compare these buildings with the buildings of our present era, there is much more variety, and more detail: there are more internal differences among the parts. There are rooms of different sizes, doors of different widths, columns of different thickness according to their place in the building, ornaments of different kinds in different places [3].

"There are small rooms opening off larger rooms; there are swellings at the places where paths meet; there are enlargements of the connection where a column meets a beam; there are more highly differentiated kinds of wood pieces in a window to correspond to the divisions between large panes and small. Edges between adjacent places are always places in themselves; they have a thickness, there is a crinkled character to them; it is almost never just a plane between two voids. There are opening between each place, and the ones next to it; and these openings occupy a fairly large percentage of the wall area. Curved lines and surfaces are rare; but they occur occasionally, at points of emphasis. Columns are thick, and often bunched or clustered. Paths are often slightly crooked, streets often taper, with minor bends in them. The character is marked, in short, by greater differences, and greater differentiation [3]."

One of the reasons for less variation and details in new buildings rather than traditional buildings; is the changing in construction ideology of elements in urban design. In the past, occupying a land and building a house in it, was according to financial ability and the extent of household. These houses in spite of external similarity, had a unique interior. But what we face today is the exact opposite of the past situation. It means the houses are very similar to each other from inside and just have a different appearance from outside. In result, the private life in houses has gotten invariable and urban space has gotten confused [2].

Variety in interior spaces of Bushehr architecture is fully featured. For example, composition of the central courtyards in Bushehr, cannot be declared by a same sentence. Central courtyards are various in several aspects. From the form and size aspect, courtyards are not square or rectangular necessarily. Square form, of course, is more common but not dominant [6]. Although most rooms are rectangular, rooms with unconventional polygon are also seen. These rooms in composition with rectangular spaces, create unique spaces. The rooms also vary in height. Rooms in lower floors have less height than upper floor rooms. In some buildings halffloor has been used. Buildings are also various in terms of syntax. In general, variations in syntax of Bushehr vernacular houses are much more than the central parts of Iran.

There are varieties in terms of walls. In some houses, courtyard is covered from four directions (like Nozari house). Najafi house is rigid on two facing walls. This variety can be effective in the function of central courtyards. This issue can be seen especially in large buildings. For example "Haj Raees" building had five central courtyards. These courtyards had different ranks. From the form and size of the courtyards can competence that which yard is private, which one is for gusts and which one is for far and near acquaintances "Fig. 1" [6].

In Bushehr architecture avoiding from colors, diversifying the façade and volumetric rotation, have become a "main characteristics". "Dehdashti" house is a beautiful example. Protrusion of floor in second and third level of "Dehdashti" house in north elevation, are completely in opposite direction "Fig. 2". Therefore, protrusion cannot be due to geometrical correction of plan, it must have had another reason [6]. The protrusions have been used as an aesthetics style to diversify the façade "Fig. 2, 6".
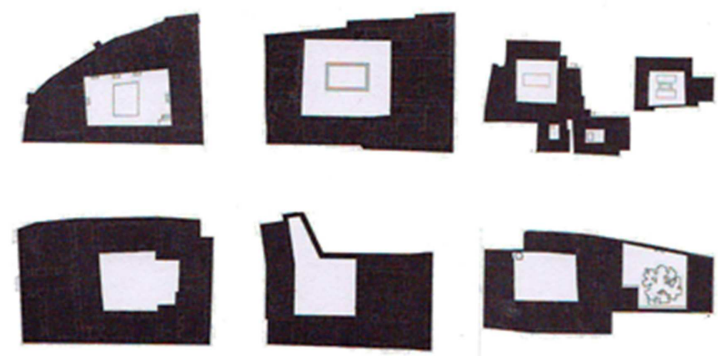

Figure 1. Variety in courtyards [7].

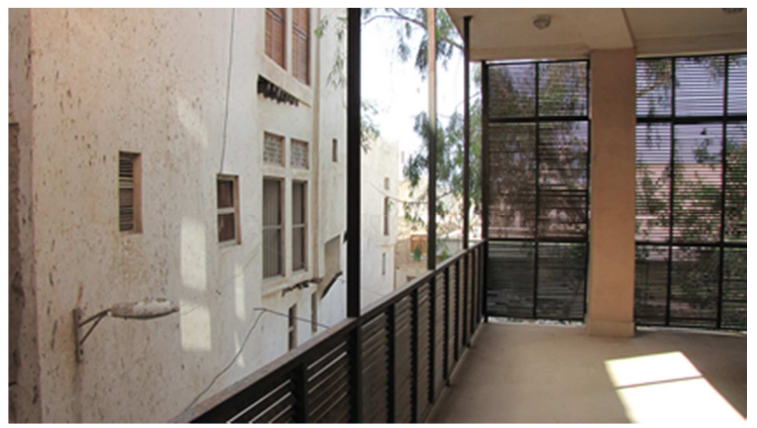

Figure 2. Protrusions on opposite directions.

\subsection{Balance Between Order and Disorder}

"Morphological identity is marked, above all, by a special balance between "order" and "disorder." There is a perfect balance between straight lines and crooked ones, between angles that are square, and angles that are not quite square, between equal and unequal spacing. This does not happen because the buildings are inaccurate. It happens because they are more accurate. The similarity of parts occurs because the forces which create the parts are always more or less the same. But the slight roughness and unevenness among these similarities, comes from the fact that forces are never exactly 
the same. The straight lines which are roughly straight, will come about because the boundary of a space must always have a space which is alive on both sides of it. A curved wall forms a concavity of space. But the straight walls are not perfectly straight, because there is no reason for them to be perfect. The angles which are roughly square will come about because few angles in a room, or in the edges of an outdoor area are comfortable if they are acute. But they are not perfectly square, because there is no reason for them to be perfect [3]."

In "Behbehani" neighborhood, there is a room in the west wall of the Kamandi house, with strange angles, low height and short windows, this room have a sight to square through windows in west wall and have a sight to central courtyard through windows in other side. Unique stairs are designed just to get to this space. In the past, this space might have been connected with adjacent space but in current situation it doesn't have direct connection whit other spaces. Some architects have used the words such as "cozy" and "lovely" to describe this space. Wall of this room, on the outside is in same direction with wall of the nearby building. And together they create a path to alley nearby. This wall is often used as a sitting place in urban space. One of the walls of this room is in line with the central courtyard and the other wall has shaped to redefine urban space "Fig. 3".

Regularity makes sense only when it's associated with irregularity and confusion. Regularity itself has no value, except in the context of its limitation. Comprehensive regularity and holistic irregularity, both make difficult conditions, which are intolerable in the long term. What architects do is something between them [1].

Buildings façades have regular and irregular aspects in Bushehr architecture. Placement of windows in a horizontal and vertical row, the same distance between the windows and the proportions of the windows, indicates the regularity in façade "Fig. 4". Most of the windows in a building, place in specific rows but there are windows which place irregularly wherever the penetration of light and air is necessary. Although these windows are placed irregularly but keeps the balance of façade "Fig. 5". Protrusions on facades are not based on any particular order. Wherever the variation is necessary in façade these protrusions are formed "Fig. 6". The "Shenashir" and its form also doesn't have specific order on facade. The combination of order and disorder is seen in buildings façades.

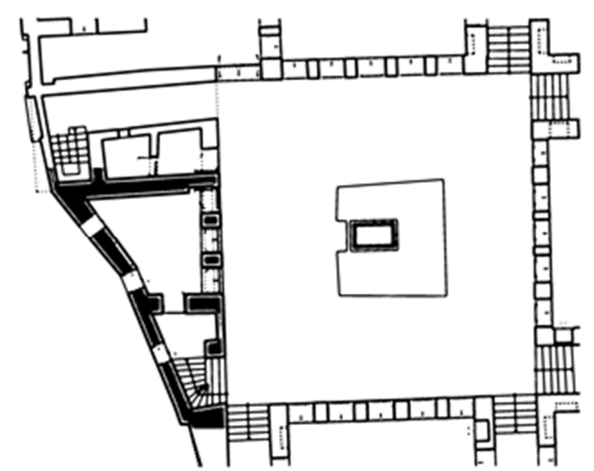

Figure 3. A room in Kamandi house with strange angles.

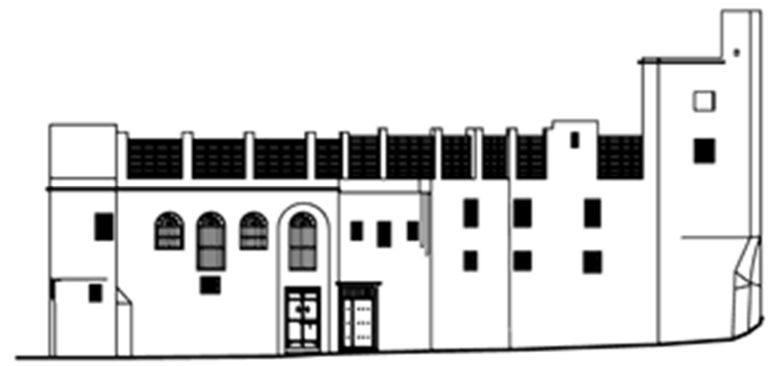

Figure 4. Placement of windows in a horizontal and vertical row, the same distance between the windows and the proportions of the windows, indicates the regularity in façade.

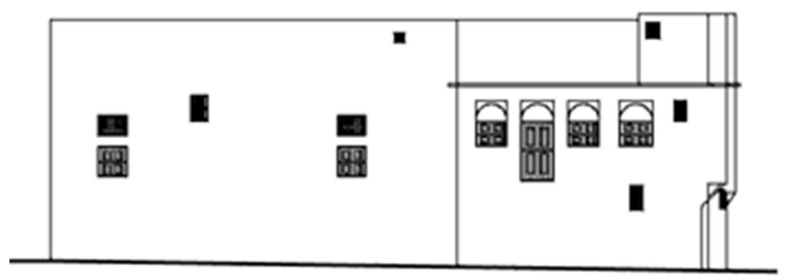

Figure 5. North elevation of kamandi house: in spite of regularity in windows placement some windows are placed irregularly.
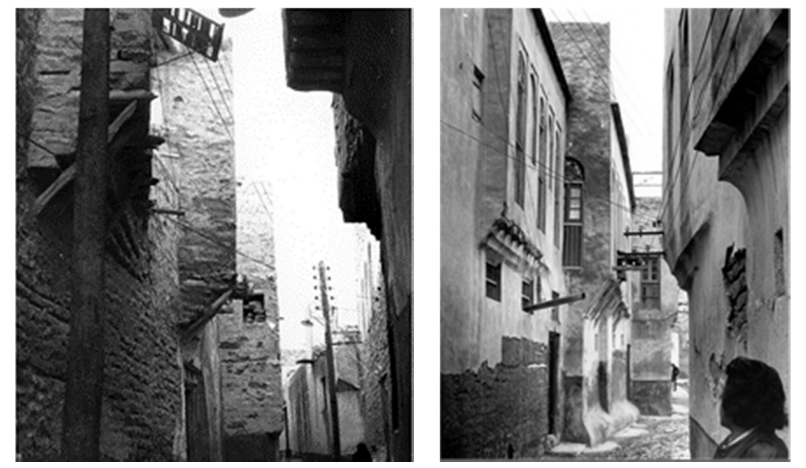

Figure 6. Protrusions on facades are not based on any particular order. Source: Technical assistance of conservation and revitalization office, Cultural Heritage of Bushehr province.

\subsection{Sharpness, Freedom and Special Atmosphere}

"Morphological identity marked, in feeling, by a sharpness and a freedom and a sleepiness which happens everywhere when men and women are free in their hearts. A few cups and glasses standing on a rough table, a handful of flowers freshly picked from the garden on the table, children playing in the corners [3]."

There is fluid relations between open, semi- open and closed spaces- In fact, between public, semi-public and private spaces- In Bushehr architecture. This issue gives quality to the interior and urban spaces and creates a special atmosphere. Combination with nature is also one of the issues that gives quality to spaces. In some cases the nature such as trees, flowers or the see is part of Bushehr architecture so that, built environment lacks something without them. The relationship between different spaces and combination with nature has created an especial atmosphere in Bushehr architecture "Fig. 6". 


\subsection{It is not Necessarily Complicated or Simple}

"It is not necessarily complicated. It is not necessarily simple. In order for a place to have this character, it does not necessarily have hundreds of small angles, funny corners, and so on. Sometimes, it is perfectly regular [3]."

Form and volumetric elegance are the aesthetics features and ornaments of buildings. Except for the colors that can be seen in the arches and other wooden elements, Bushehr architecture has no color variation. All the body and feature of Bushehr architecture can be defined, monotonous white. Purity and simplicity of the new architecture can be seen here. Simplicity and purity in form, volume and color are indications of Bushehr architecture [6].

\subsection{Each Part Becomes Whole in Its Own Terms}

"The boundaries between things are less marked; they overlap with other boundaries in such a way that the continuity of the world, at this particular place, is greater [3]." "Each thing is made of parts, but the parts overlap and interlock to such an extent that the oneness of all things becomes more marked. There are no gaps between the parts, because each gap is just as much a part itself [3]." "Under the guidance of a process which allows wholes to form, at different scales. Each part becomes whole in its own terms, because it is adapted to the larger wholes which it is part of, and because it is adapted to the smaller wholes which are a part of it [3]."“"Then the world becomes one. There is a continuum of order, which leaves the parts indistinct and unified [3]."

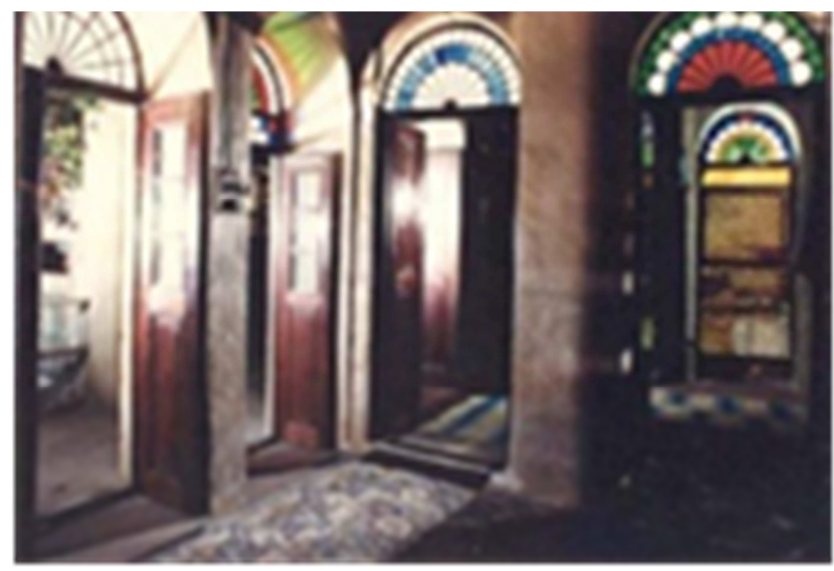

Figure 6. Special atmosphere of architecture, source: Safi.

Inclusive regularity that unite the components can be called "cohesion". Eye, selects and combines the elements, it is in search of easiest and most abstract form and tries to merge different parts. The cohesion of a work of art can have its own internal logic that neither with natural science nor with science of interpretation is not known. A work is made up of parts that together have the effect of category and group. The principle of sorting or grouping is strengthened by repetition, similarity, proximity, common framework, symmetry and orientation of sections. Even, sometimes the unity in meaning has a role in cohesion [1].
Systematic cohesion factors in architecture and urban design are ubiquitous and form their foundation. In most systems, several factors simultaneously, play their role. Reality is complex and unique situations are rare. Sometimes one factor prevails over the others. Due to the simultaneous action of four factors (similarity, proximity, frame, orientation) which have different levels of influence; an architectural work, even with being heterogeneous and asymmetric can become an inseparable complex [1].

A whole is created By the Relation of building elements on small scale, parts of a building on medium scale and eventually all parts of a building or even parts of the city on a large scale. The expression power of the whole depends on three factors: the number of parts, type of parts and parts relationships with each other that is established by a regulatory system [11].

In old tissue of Bushehr most of the buildings have central courtyard. Such buildings have a central organization pattern. But urban tissue has a free organization. "In free organization a comprehensive order is not recognizable. Such groups have emerged over time and have not been pre-designed. The structure of these collections is spontaneous. The beginning point in them can be a square, a specific place or even a building which been there before the others [11]." In this organization when a single component like a building becomes an absolute essential part of a whole, it can be said that there is an organic order [12].

In old tissue of Bushehr different parts has been related to each other by a complicated system. These parts are from the "complete type" which means that they can be built alone as a complete independent and self-sufficient structure. Formal similarity and various circulation paths have helped to shape this tissue as an interconnected whole.

\subsection{Reflecting the Forces in Them Properly}

"The proper order for a building or a town, which comes about when buildings are correctly fitted to the forces in them, is a much rich order, with a far more complex geometry. But it is not merely rich and complex; it is also very specific. And it will show itself, under any circumstances, where buildings are actually correct. Whenever anyone manages to make a building which is alive, it will have this specific character, because that is the only character which is compatible with life [3]."

"The character belongs to buildings which reflect the forces in them properly. The prismatic buildings of our own time, the buildings built with the simple geometry of cubes, and circles, spheres, and spirals, and rectangles; this geometry is the naïve order, created by the childish search for order. We happen to think of this order as the proper order for a building, because we have been taught to think so; but we are wrong [3]."

"It is true that many of the historic styles of building have some quality in common they have it not because they are old, but because man has, over and over again, approached the secret which is at the heart of architecture. In fact, the principles which make a building good, are simple and direct they follow directly from the nature of human beings, and the laws of nature. and any person who penetrates these laws will, 
as he does so, come closer and closer to this great tradition, in which man has sought for the same thing, over and over again, and come always to the same conclusions. As you learn to make buildings more and more alive, and thereby more and more true to their own nature, you will inevitably approach this timeless character [3]."

Form and volume in bushehr architecture has a cultural aspect which is derived from the type of livelihood and life in two previous centuries. Living in bushehr required interaction and diversity in that time and architecture should have reflect that culture [6]. Bushehr cultural space in the late nineteenth and early twentieth century, was training the multicultural and free ambience of European world. Extraordinary cultural diversity due to the presence of diplomats and officials from more than ten large and small countries in Bushehr port with the dominant trade and commerce character of the city; was a suitable context for variety of thought and breaking the cultural and aesthetics frame of the landlord community. The fluid relation between the inside and outside of the home is an architectural answer to free and fluid social relationships in the environment. In such a cultural context and aesthetic tastes, purity and unity enter to architecture and Ornaments lose their central role. In result the building is shown as it is and is seen as its own nature [6].

The timeless character of buildings is as much a part of nature as the character of rivers, hills, flames, and stars. Each class of phenomena in nature has its own characteristic morphology. And when buildings are made properly, and true to all the forces in them, then they too will always have their own specific character. This is the character created by the timeless way." "It is the physical embodiment, in towns and buildings, of the quality without a name [3]."

\section{Conclusion}

Each architecture has its own studying method. For recognizing the nature of an architecture, it should be studied with an appropriate viewpoint. Recognizing the characteristics of morphological identity in Bushehr architecture and its manifestations is one of the goals of this research. Christopher Alexander's theory about the morphological identity of the old buildings, since it is general and also corresponded with Bushehr architecture, is suitable for this purpose. Bushehr architecture, have its own especial morphological patterns and spatial syntax. In this respect, Bushehr architecture is very diverse and pluralistic. The balance between order and disorder, both in buildings and in urban context has been established. Regarding purity of volume and form, buildings are simple but they are complicated in terms of variety in façade, volumetric rotation and Protrusions on the façade. Bushehr old tissue, like other ancient tissues, is cohesive, unified and integrated. Bushehr architectural style which is completely free of any kind of rigidity and unnecessary symmetry has caused the sincere expression of forces in the buildings. Therefore the form and volume changes wherever it is necessary. Bushehr architecture is valuable and signs of wisdom can be seen in it.

\section{References}

[1] P. V, Meiss, "Elements of architecture: from form to place", Routledge, New York, 2011.

[2] M, Ghasemi Esfahani, "Where are we from? (Identifying the residential tissues)”, Rozaneh, Tehran, 2004.

[3] C, Alexander, "The timeless way of building", Oxford University Press, New York, 1979.

[4] N, Shabani, and M, Kouchakzadeh and A, Shaibi, "Revitalization of Old and Valuable Tissues by Establishing Proper Functions; Case study: Old Tissue of Bushehr", Journal of Soffeh, 45, Tehran, pp: 54-67, 2007.

[5] B, Marbaghi, "The story of the first street in port of Boshehr", Journal of Memari va Farhang, No. 47, 2012, pp: 44- 49.

[6] B, Marbaghi, "Modern concepts in architecture of Bushehr", Payam, Tehran, 2013.

[7] A, Kolivand, "Spatial- Physical features of bushehr old tissue", Journal of Abadi, 12, 2002, pp: 57- 60.

[8] J, Kabiri, "Recycling of old housing in Bushehr", thesis on architectural engineering (M. Sc), Shahid Beheshti University, Tehran, 1995.

[9] B, Marbaghi, and Kerman Citadel of Bam Consulting Engineers, "Consulate of Britain, Bushehr", Journal of Memer, 55, 2009, pp: 97-101,

[10] S. B, Hosseni and M, Alalhesaby and F, Nasabi, "Analyzing urban environment by the approach of visual quality (case Study: old Tissue of Bushehr)", Journal of Hoviate Shahr, 8, 2004, pp: 83-91.

[11] Grütter, J. K, “Ästhetik der Architektur Grundlagen der Architektur-Wahrnehmung”, W. Kohlhammer, Stuttgart, 1987.

[12] Wölfflin, H, "Kunstgeschichtliche Grundbegriffe", Basel, 1984. 